\title{
The relation of sensation in the anal canal to the functional anal sphincter: a possible factor in anal continence
}

\author{
H. L. DUTHIE AND R. C. BENNETT \\ From the University Department of Surgery, Leeds
}

EDITORIAL SYNOPSIS In normal subjects the length of the functional anal sphincter has been compared with the extent of sensation to light touch in the anal canal. At rest, the sphincteric zone was the longer. On distension of the rectum, a decrease in pressure in the anal canal so shortened the functional sphincter that intrarectal pressure extended down to contact the sensory zone. This mechanism may allow the sensation in the anal canal to play a part in the fine adjustment of anal continence.

The epithelium of the anal canal has been shown to be profusely supplied with sensory nerve endings up to $1 \mathrm{~cm}$. proximal to the anal valves, and the sensations of light touch, pain, heat, and cold are present within this area (Duthie and Gairns, 1960). It was postulated that if rectal contents could contact this sensitive part of the anal canal they might contribute additional sensory information assisting the maintenance of anal continence. In the present study the functional length of the anal sphincter has been measured and compared with the extent of the sensation of light touch in the anal canal. It will be shown that rectal contents could impinge upon the sensory area of the anal canal.

\section{MATERIAL AND METHODS}

Twenty-nine normal male subjects, aged 20 to 65 years, were studied. They showed no pathological condition of the anorectal region on examination and enjoyed normal anal function. Tests were carried out in the forenoon, two to four hours after a light breakfast, the subject lying in the left lateral position. No preparatory enema was given and the presence of faeces in the rectum precluded testing. An indelible mark was placed at the anal verge and all distances measured from it. Sensation to light touch in the anal canal was tested with a fine bristle mounted at right angles on a thin graduated metal handle which had a sliding segment to facilitate accurate measurement of distance. A McEvedy's rectal speculum was used to hold the anal canal open. The most craniad measurement was recorded, as interest was in the highest level of sensation.

The length of the functional anal sphincter was measured by withdrawing a small pressure-detecting unit from the rectum through the anal canal. An increase of pressure above that in the rectal ampulla was taken to indicate the upper edge of the sphincter. This increase was usually definite over a distance of $0.5 \mathrm{~cm}$. In a few instances a change of position of $1 \mathrm{~cm}$. was required before a clear trend was established. No attempt has been made to distinguish between the internal and external anal sphincter and the pubo-rectalis sling. The whole complex has been designated the functional anal sphincter.

The pressure detecting unit was a fine polythene tube (internal diameter $1.5 \mathrm{~mm}$.) which was placed in the rectum through a small bore Lloyd-Davies sigmoidoscope. This tube was filled with water and connected to a Statham strain gauge (P $23 \mathrm{~Gb}$ ), the output of which was amplified and recorded on photographic paper (cardiac recorders, type $24 \mathrm{E}$ ). The open-ended tube was then withdrawn in steps of $0.5 \mathrm{~cm}$., the pressure being recorded at each step. Two such withdrawals were performed and the average taken. After a rest period the pressure engendered by voluntary contraction of the sphincter was measured.

Identical results were obtained if the fine polythene tube had a side instead of a terminal opening. When a small air-filled balloon, $3 \times 10 \mathrm{~mm}$., was attached to the end of the polythene tube, the pressures recorded were slightly higher. The results reported are with the openended unit.

In 19 subjects further testing was done with three fine polythene tubes. One had a balloon tip which was placed with its caudad end $10 \mathrm{~cm}$. from the anal verge. When inflated with $100 \mathrm{ml}$. air the balloon measured $7 \times 5 \mathrm{~cm}$. in atmospheric air. The remaining two tubes were openended. One was placed with its tip 6 to $7 \mathrm{~cm}$. from the anal verge to provide a constant measurement of rectal ampullary pressure. The other was withdrawn in steps of $0.5 \mathrm{~cm}$. as above. At each step the balloon was 


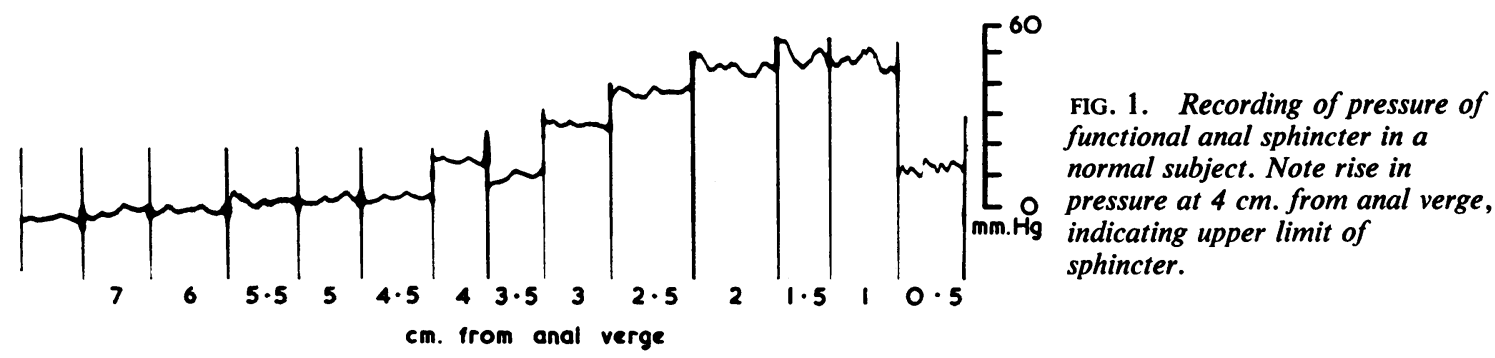

inflated with $100 \mathrm{ml}$. of air and the change in intrarectal and anal sphincteric pressure measured as above by means of Statham strain gauges (P $23 \mathrm{~Gb}$ ).

\section{RESULTS}

SENSATION Light touch was appreciated to a level of from 2.5 to $5 \mathrm{~cm}$. from the anal verge (mean 3.1 $\mathrm{cm} . \pm 0.10 \mathrm{~cm}$. S.E.M.). The anal valves were situated from 0.3 to $1.5 \mathrm{~cm}$. caudad to this level, the mean distance from the anal verge being $2 \cdot 0 \mathrm{~cm}$. $( \pm 0.22 \mathrm{~cm}$. S.E.M.).

FUNCTIONAL ANAL CANAL Measurements were taken with the subjects at rest, with voluntary contraction, and with rectal distension.

At rest The increase in pressure due to the functional anal sphincter occurred at from 5 to $3 \mathrm{~cm}$. from the anal verge (mean $3.8 \mathrm{~cm} . \pm 0 \cdot 11$ S.E.M.) (Fig. 1). When this distance was compared with the level of sensation in each subject, the functional anal sphincter was found to extend craniad to sensation in 25 of the 27 so tested, so that the sensory level of the anal canal was effectively shut off from any rectal contents. The pressure on withdrawal through

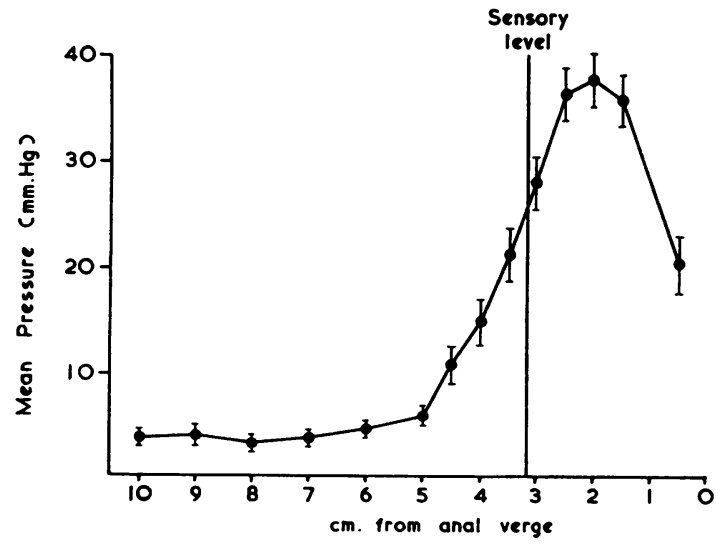

FIG. 2. Diagram of mean pressures of functional anal sphincter compared with level of sensation in the anal canal in 29 normal subjects. The line through each reading indicates the standard error of mean. the anal sphincteric zone rose as high as $70 \mathrm{~mm}$. of mercury. The maximal pressure was at 2.0 to 1.0 $\mathrm{cm}$. from the anal verge (mean $1.9 \mathrm{~cm}$. $\pm 0.13 \mathrm{~cm}$. S.E.M.). The mean pressures for each level are illustrated in Figure 2.

With voluntary contraction Within the rectal ampulla voluntary contraction of the anal sphincter produced either no change or an increase in pressure of a few millimetres of mercury. In the anal sphincteric zone, pressure increased from 10 to $50 \mathrm{~mm}$. of mercury, giving maximal pressures of from 60 to $100 \mathrm{~mm}$. of mercury. Pressure could only be maintained voluntarily for up to one minute.

With rectal distension The pressure in the rectal balloon after inflation with $100 \mathrm{ml}$. air was from 40 to $60 \mathrm{~mm}$. of mercury, which gave rise to a feeling of fullness in the perineum in all subjects. Within one second the pressure in the anal sphincteric zone diminished (Fig. 3), slowly returning towards normal in one to two minutes. The mean pressures immediately before inflation of the balloon are compared with those at maximal decrease in Figure 4. It can be seen that the relaxation in the anal sphincteric zone was greater in the craniad portion and that the caudad $2 \mathrm{~cm}$. showed less change. The mean pressures show that intrarectal pressure could reach the mean uppermost level of anal canal sensation. In the individual subject, this clearly occurred in 13 of 17 in whom complete data are available and as much as $2 \mathrm{~cm}$. of the sensory area could be so reached (Table I). In two other subjects the results were similar but a rather small margin was found, 0.1 and $0.3 \mathrm{~cm}$. respectively. In the remaining two subjects the sensory area was not so exposed.

\section{DISCUSSION}

The measurement of the level to which sensation to light touch extended up the anal canal confirmed results previously reported (Duthie and Gairns, 1960). It must be noted that sensory testing was done against the inevitable background stimulus caused by the presence of the rectal speculum in the anal canal. With the subject at rest, the height at which the anal sphincteric pressure zone commenced was 

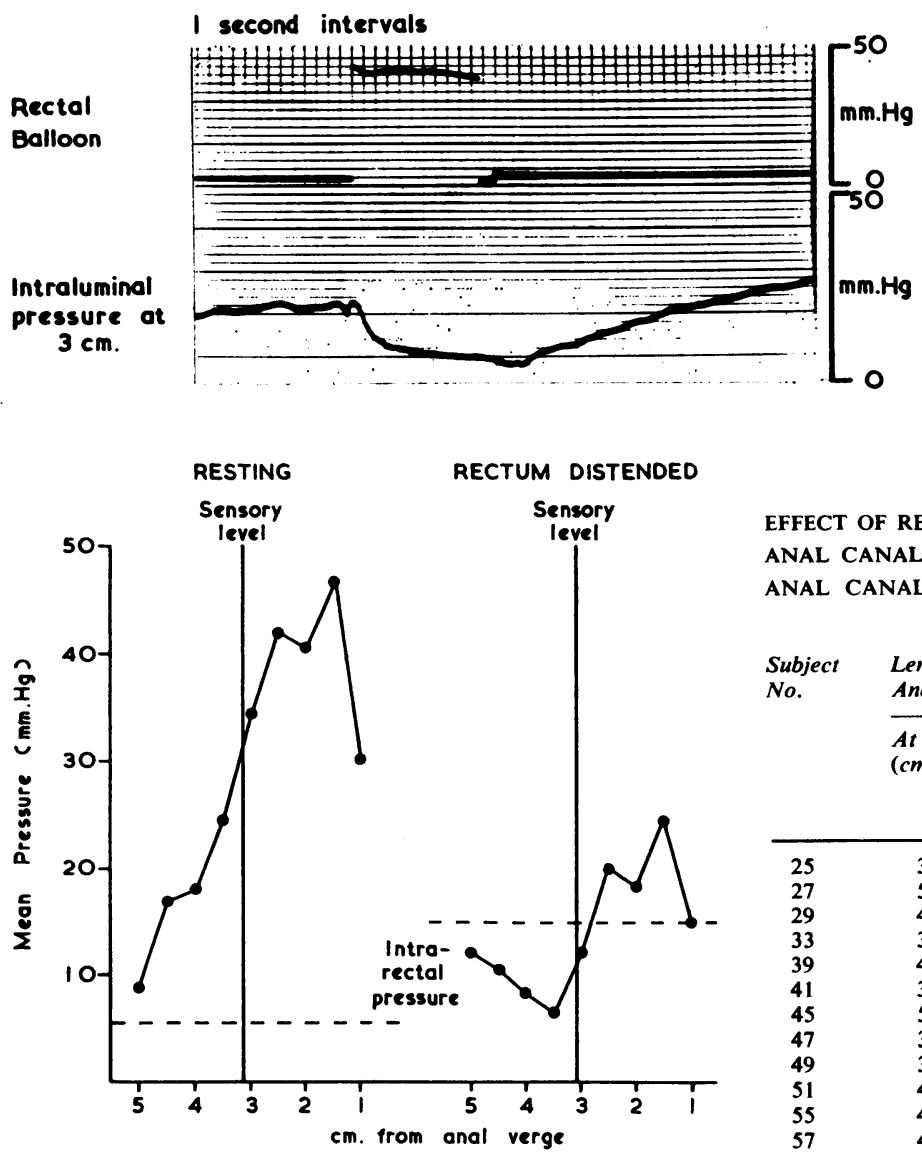

FIG. 4. Comparison of pressures in the anal sphincteric zone at rest and during distension of the rectum in 19 normal subjects. Intrarectal pressure, measured with a separate unit, is also shown.

similar to that noted by other workers using comparable techniques (Hill, Kelley, Schlegel, and Code, 1960). When these levels were compared it was seen that intrarectal pressure failed to reach the sensory zone in almost all subjects. Thus, at rest, the anal canal sensory mechanism could play no part in detecting the nature of rectal contents.

When the entry of material into the upper rectum was simulated by inflation of a balloon placed at $10 \mathrm{~cm}$. in the rectum, a decrease in pressure in the anal sphincteric zone was noted, a finding made several years ago with rather larger pressurerecording devices (Denny-Brown and Robertson, 1935; Gaston, 1948).

The apparent decrease might be due to an artefact, the balloon stretching the rectum and pulling the lining of the anal canal away from the recording tip. It is most difficult to obtain direct evidence on
FIG. 3. Response of anal sphincteric pressure at $3 \mathrm{~cm}$. from anal verge (lower tracing) to inflation of a balloon at $10 \mathrm{~cm}$. in the rectum (upper tracing).

TABLE I

EFFECT OF RECTAL DISTENSION ON LENGTH OF FUNCTIONAL ANAL CANAL SHOWING THE LENGTH OF SENSORY ZONE OF ANAL CANAL EXPOSED TO INTRARECTAL PRESSURE IN 15 OF 17 NORMAL SUBJECTS

\begin{tabular}{|c|c|c|c|c|}
\hline \multirow[t]{2}{*}{$\begin{array}{l}\text { Subject } \\
\text { No. }\end{array}$} & \multicolumn{2}{|c|}{$\begin{array}{l}\text { Length of Functional } \\
\text { Anal Sphincter }\end{array}$} & \multirow{2}{*}{$\begin{array}{l}\text { Length of } \\
\text { Sensory } \\
\text { Zone } \\
(\mathrm{cm} .)\end{array}$} & \multirow{2}{*}{$\begin{array}{l}\text { Length of } \\
\text { Sensory Zon } \\
\text { Exposed to } \\
\text { Intrarectal } \\
\text { Pressure } \\
\text { (cm.) }\end{array}$} \\
\hline & $\begin{array}{l}\text { At Rest } \\
(\mathrm{cm} .)\end{array}$ & $\begin{array}{l}\text { With } \\
\text { Rectal } \\
\text { Distension } \\
\text { (cm.) }\end{array}$ & & \\
\hline
\end{tabular}

\begin{tabular}{|c|c|c|c|c|}
\hline 25 & 3.0 & 1.5 & $2 \cdot 7$ & $1 \cdot 2$ \\
\hline 27 & $5 \cdot 0$ & $2 \cdot 5$ & 3.0 & 0.5 \\
\hline 29 & $4 \cdot 5$ & $2 \cdot 5$ & $3 \cdot 2$ & 0.7 \\
\hline 33 & $3 \cdot 5$ & $1 \cdot 5$ & 3.5 & $2 \cdot 0$ \\
\hline 39 & $4 \cdot 5$ & 3.0 & 3.0 & - \\
\hline 41 & 3.0 & 2.0 & $2 \cdot 7$ & 0.7 \\
\hline 45 & 5.0 & 3.0 & 3.7 & 0.7 \\
\hline 47 & 3.0 & $2 \cdot 5$ & 2.6 & 0.1 \\
\hline 49 & 3.5 & 1.5 & $2 \cdot 3$ & 0.8 \\
\hline 51 & $4 \cdot 5$ & 3.0 & $3 \cdot 3$ & 0.3 \\
\hline 55 & $4 \cdot 0$ & $2 \cdot 5$ & 3.4 & 0.9 \\
\hline 57 & 4.0 & 3.0 & $4 \cdot 0$ & 1.0 \\
\hline 59 & $4 \cdot 5$ & $2 \cdot 0$ & 3.0 & $1 \cdot 0$ \\
\hline 61 & 5.0 & 2.5 & 3.0 & 0.5 \\
\hline 65 & 4.0 & 1.5 & 2.0 & 0.5 \\
\hline 67 & $4 \cdot 0$ & $2 \cdot 5$ & 3.6 & $1 \cdot 1$ \\
\hline 69 & $4 \cdot 5$ & $4 \cdot 0$ & $2 \cdot 8$ & - \\
\hline Mean & $4 \cdot 1$ & $2 \cdot 4$ & 3.0 & 0.8 \\
\hline S.E.M. & 0.18 & 0.17 & 0.12 & $0 \cdot 12$ \\
\hline
\end{tabular}

this suggestion but some findings seem to be against it. First, the lower edge of the balloon was placed $10 \mathrm{~cm}$. from the anal verge, some $6 \mathrm{~cm}$. craniad to the upper part of the anal canal. Its maximal diameter in atmospheric air was $5 \mathrm{~cm}$. when inflated. It would seem rather small and distant to be able to cause the postulated effect. Second, when the balloon was inflated it had only a slight effect on intrarectal pressure, causing an increase of about $10 \mathrm{~mm}$. of mercury. Third, relaxation in the sphincteric zone was passing off before any appreciable change in the distending pressure of the balloon.

The recorded decrease in pressure was most marked in the craniad portion of the sphincteric zone and resulted in a pressure lower than that in the rectal ampulla. With the distending force used in 
this study, the caudad portion maintained sufficient pressure for continence.

Assessment of the level to which intrarectal pressure extended was limited in accuracy by the fact that measurements of pressure were only done at $0.5 \mathrm{~cm}$. intervals. As a result, on withdrawal of the recording tip, a point was reached when sphincteric pressure remained above intrarectal pressure after distension of the rectum by the balloon. The measurement $0.5 \mathrm{~cm}$. craniad to this was taken as the lowest level to which intrarectal pressure extended. It can be seen that this assessment might have been as much as $4 \mathrm{~mm}$. too far craniad. As this error would tend to minimize rather than exaggerate any exposure of the sensory zone of the anal canal, it was felt to be acceptable.

The relaxation of the sphincteric zone allowed intrarectal pressure to extend down to contact the sensory part of the anal canal in 15 of 17 subjects. The rapidity of the response would allow any bolus entering to be 'sampled' by the anal canal and thus assist in determining the appropriate voluntary action. The ample reserve of voluntary power was demonstrated by the pressure of up to $100 \mathrm{~mm}$. mercury recorded on contraction of the anal sphincter.

It is not suggested that this anal sensory mechanism is involved in the urge to defaecate, but rather that it operates promptly when the rectum is distended to add a fine discrimination to the vague feeling of fullness in the perineum and probably allows the distinction between flatus and faeces to be made. It seems a likely explanation for the burning urgency which is associated with the presence of fluid faeces in the rectum.

We thank Professor J. C. Goligher for his keen interest and encouragement throughout this study.

\section{REFERENCES}

Denny-Brown, D., and Robertson, E. G. (1935). An investigation of the nervous control of defaecation. Brain, 58, 256-310.

Duthie, H. L., and Gairns, F. W. (1960). Sensory nerve-endings and sensation in the anal region of man. Brit. J. Surg., 47, 585-595.

Gaston, E. A. (1948). Fecal continence following resection of various portions of the rectum with preservation of the anal sphincters. Surg. Gynec. Obstet., 87, 669-678.

Hill, J. R., Kelley, M. L. Jr., Schlegel, J. F., and Code, C. F. (1960) Pressure profile of the rectum and anus of healthy persons. Dis. Colon Rect., 3, 203-209. 